\title{
Evaluation of polybutadiene rubbers using FTIR spectra
}

\author{
L. N. Oliveira ${ }^{\mathrm{a}, \mathrm{b}}$, S. L. Vieira ${ }^{\mathrm{c}}$, F. Schimidt ${ }^{\mathrm{a}}$, P. L. Antonio $^{\mathrm{b}}$, L.V.E. Caldas ${ }^{\mathrm{b}}$ \\ ${ }^{a}$ Instituto Federal de Educação, Ciência e Tecnologia de Goiás-IFG, Campus Goiânia, Goiânia-GO, Brazil \\ ${ }^{b}$ Instituto de Pesquisas Energéticas e Nucleares, Comissão Nacional de Energia Nuclear, São Paulo-SP, Brazil \\ ${ }^{c}$ Instituto de Física, Universidade Federal de Goiás-UFG, Campus Samambaia, Goiânia-GO, Brazil \\ lucas@ifg.edu.br
}

\begin{abstract}
Radiation dosimetry for medical and industrial purposes has increasingly evolved over the last few decades with the introduction of various new detectors. Depending on the properties exhibited for radiation dosimetry, some detectors present their applications in a specific area. From a physics point of view, an ideal dosimeter should be able to measure absorbed dose. In this work, synthetic materials based on polybutadiene rubbers (PBR) were proposed as a new class of radiation detectors. The influence of radiation dose on their properties has been investigated for application in radiation dosimetry. The rubber samples were exposed to absorbed doses from $10 \mathrm{~Gy}$ up to $250 \mathrm{~Gy}$, using a ${ }^{60} \mathrm{Co}$ Gamma Cell-220 system. Their responses were carried out with a Fourier Transform Infrared (FTIR) Spectrometer to investigate the presence of absorbance peaks. The results suggested the existence of a relationship between the absorbed doses and the absorbance peaks associated with stretching (1300-1200 $\left.\mathrm{cm}^{-1}\right)$, deformation $\left(1450-1340 \mathrm{~cm}^{-1}\right)$ and vibration $\left(1500-1400 \mathrm{~cm}^{-1}\right)$ processes in the material.
\end{abstract}

Keywords: radiation, dosimetry, detectors 


\section{INTRODUCTION}

In the recent years radiation processing of polymers has been used to modify the molecular structure of the components as an alternative to the more traditional chemical methods, i.e., gamma radiation has been used to induce vulcanization [1,2]. Radiation-induced polymerization and crosslinking of appropriate monomers were embedded in a polymeric matrix. The polymerization alters a number of chemical and physical properties of the polymer network. Alteration in the chemical properties by radiation is strictly related to generation of free radicals that are formed by dissociation of the excited states or by ion molecular reactions [3]. The irradiation process results in change in both molecular structure and macroscopic properties of the polymer. Aggregation of the monomers chain by intermolecular force creates the physical crosslinking region. The main changes induced by radiation in polymers are related to mechanical properties, such as tensile strength and elongations, which are commonly reported [4,5]. Physical-chemical crosslinking density affects the physical and chemical properties of irradiated polymer.

For medical applications the measurement of the absorbed dose delivered by ionizing radiation in polymers is an exciting scientific field of research, so-called Dosimetry. Research has been performed to develop new classes of polymers sensible to radiation as possible candidates for use in dosimetry [6-8].

In this work the influence of radiation dose in synthetic rubber as polybutadiene was studied. The response of the irradiated samples was carried out with a Fourier Transform Infrared Spectroscopy-FTIR system to investigate the presence of absorbance peaks and their correlation with absorbed dose.

\section{MATERIALS E METHODS}

The polybutadiene rubber analyzed is commercially known as BR 45 that is produced and distributed by Petroflex (Cabo de Santo Agostinho, Pernambuco, Brazil). The polymer is produced by continuous polymerization of 1,3-butadiene in solution with stereospecific initiator of type 
alkyllithium. Its polymer chain structure is predominantly linear with microstructure comprising $36 \%$ of "1,4-cis" units, $56 \%$ "1,4-trans" units and $8 \%$ of "1,2-vinyl" units. The polymer is stabilized with non-staining antioxidants and features light color [9].

The polybutadiene rubber samples used in this work were composed by small cubes with size approximately of $1 \mathrm{~cm}^{3}$. The rubber samples were irradiated with absorbed doses of 10, 50, 100 and $250 \mathrm{~Gy}$, using a ${ }^{60} \mathrm{Co}$ Gamma Cell-220 system (dose rate of $1.089 \mathrm{kGy} / \mathrm{h}$ ); afterwards, the absorbance spectrum of each sample was acquired on a Fourier Transform Infrared (FTIR) Spectrometer (Frontier/Perkin Elmer). The spectra were collected on the range of 1500 to $1000 \mathrm{~cm}^{-1}$, resolution of $4 \mathrm{~cm}^{-1}$, scan interval of $1 \mathrm{~cm}^{-1}$, and 16 acquisitions (12 irradiated, 3 samples for each dose and 4 non-irradiated). The absorbance peaks were observed for each rubber sample.

\section{RESULTS AND DISCUSSION}

In Figure 1 the FTIR Spectroscopy spectra for polybutadiene samples are shown for different absorbed doses of gamma radiation. The peaks are shown with their respectively wave numbers. The polybutadiene samples present characteristic absorptions from $\mathrm{CH} 2$ vibration on $1500-1400$ $\mathrm{cm}^{-1}$; CH2 stretching on 1300-1200 $\mathrm{cm}^{-1}$ and also CH2 deformation on $1450-1340 \mathrm{~cm}^{-1}$ [10].

In Figure 2 the dose-response curves obtained from irradiations with the ${ }^{60} \mathrm{Co}$ Gamma Cell-220 system are shown for the polybutadiene samples. The wave numbers of 1020, 1239, 1307, 1404, 1433 and $1448 \mathrm{~cm}^{-1}$ were analyzed; their correspondent absorbance peaks are depicted in Figure 1. In the selected results the absorbance was obtained subtracting the value of $A_{n}$ (absorbance of the irradiated samples with $\mathrm{n}=10,50,100$ and $250 \mathrm{~Gy}$ ) from $\mathrm{A}_{0}$ (absorbance from a non irradiated sample $\mathrm{n}=0 \mathrm{~Gy}$ ). For each wave number of 1020, 1239, 1307, 1404, 1433 and $1448 \mathrm{~cm}^{-1}$ the following sensibilities values were obtained: $0.2250 ; 0.2442 ; 0.3038 ; 0.3111,0.3510$ and $0.3528 \mathrm{~Gy}^{-1}$ respectively (the sensibility is defined as ratio between absorbance $\left(\mathrm{A}_{\mathrm{n}}-\mathrm{A}_{0}\right)$ by absorbed dose for each wave numbers). A linear fit was applied to the data and linearity of re- 
sponse with absorbed dose can be observed for all cases. The lowest data correlation factor was obtained for the wave number of $1020 \mathrm{~cm}^{-1}, \mathrm{R}^{2}=0.9996$.

Figure 1: FTIR spectra from 1000 to $1500 \mathrm{~cm}^{-1}$ for polybutadiene samples exposed to different absorbed doses of gamma radiation.

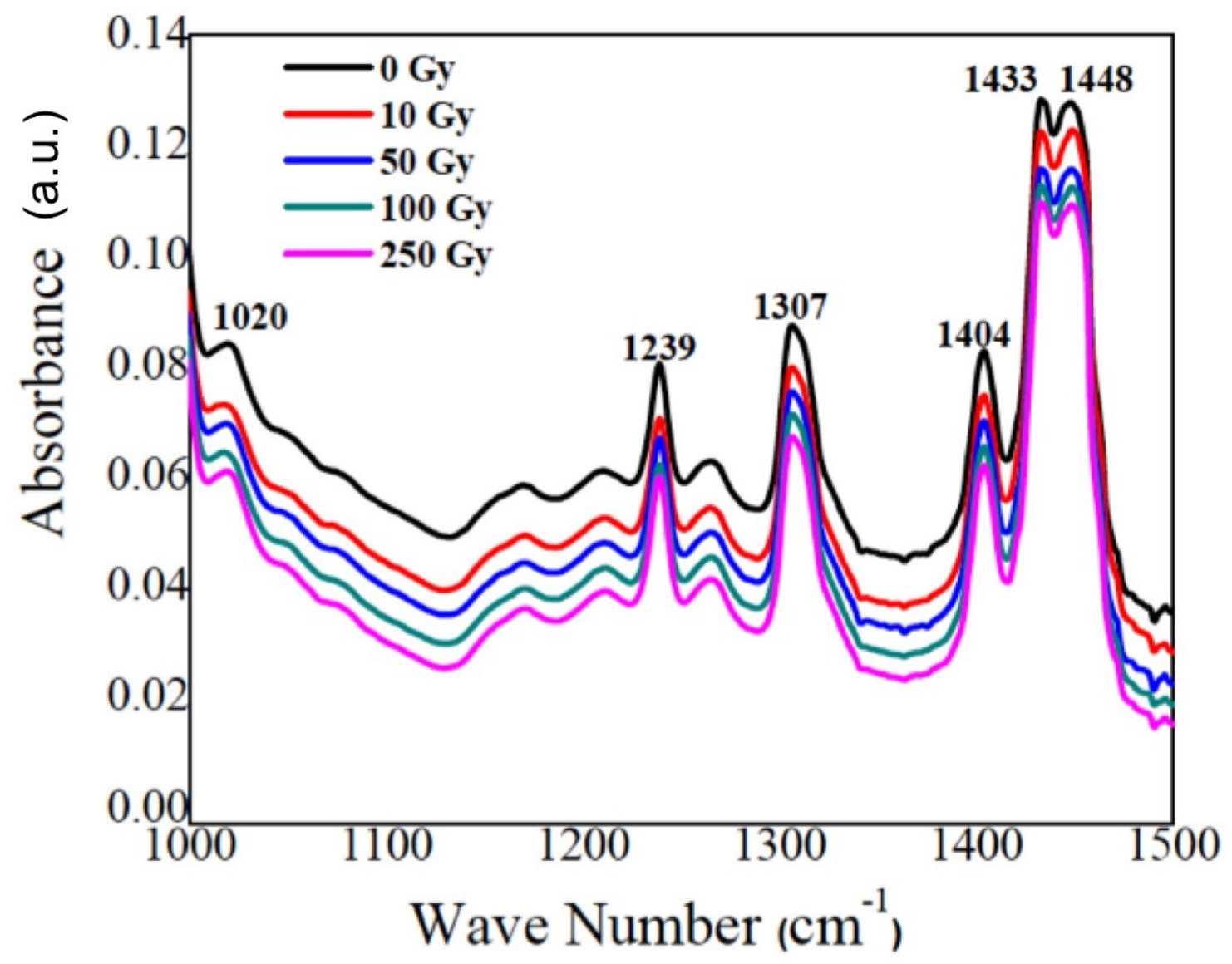

Source: Authors.

In Figure 3 the absorbance versus absorbed dose of polybutadiene rubber is shown; these curves are associated with stretching (1300-1200 $\left.\mathrm{cm}^{-1}\right)$, deformation (1450-1340 $\left.\mathrm{cm}^{-1}\right)$ and vibration (1500-1400 $\mathrm{cm}^{-1}$ ) caused by irradiation in the polybutadiene samples. For each cited region the measurements were obtained through media values three from spectra region, and they were approximated by an exponential function. From these results, it can be seen that the properties of stretching and deformation have similar results as a function of the absorbed dose while the vibration presents lower value, probably due to the rigidity of the studied rubber samples. 
Figure 2. Dose-response curves for polybutadiene samples exposed to different absorbed doses of gamma radiation.

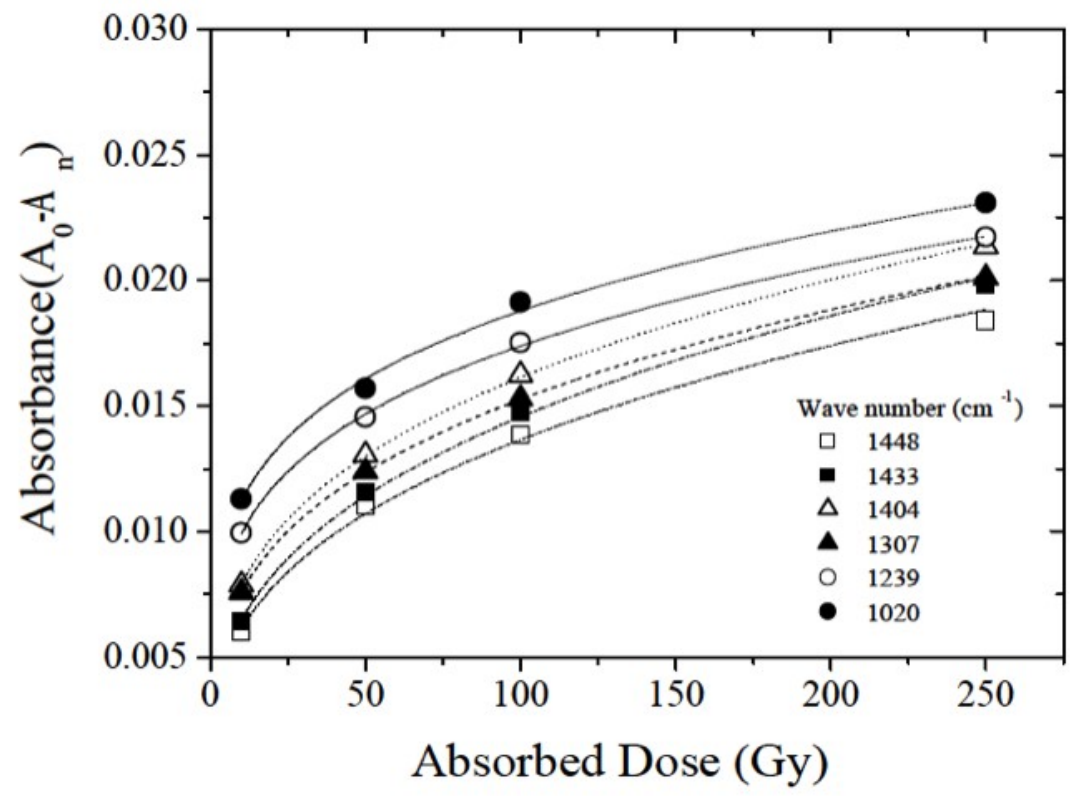

Source: Authors.

Figure 3. Absorbance of polybutadiene rubber versus absorbed dose of gamma radiation; these results are associated with stretching, deformation and vibration caused by irradiation in polybutadiene samples.

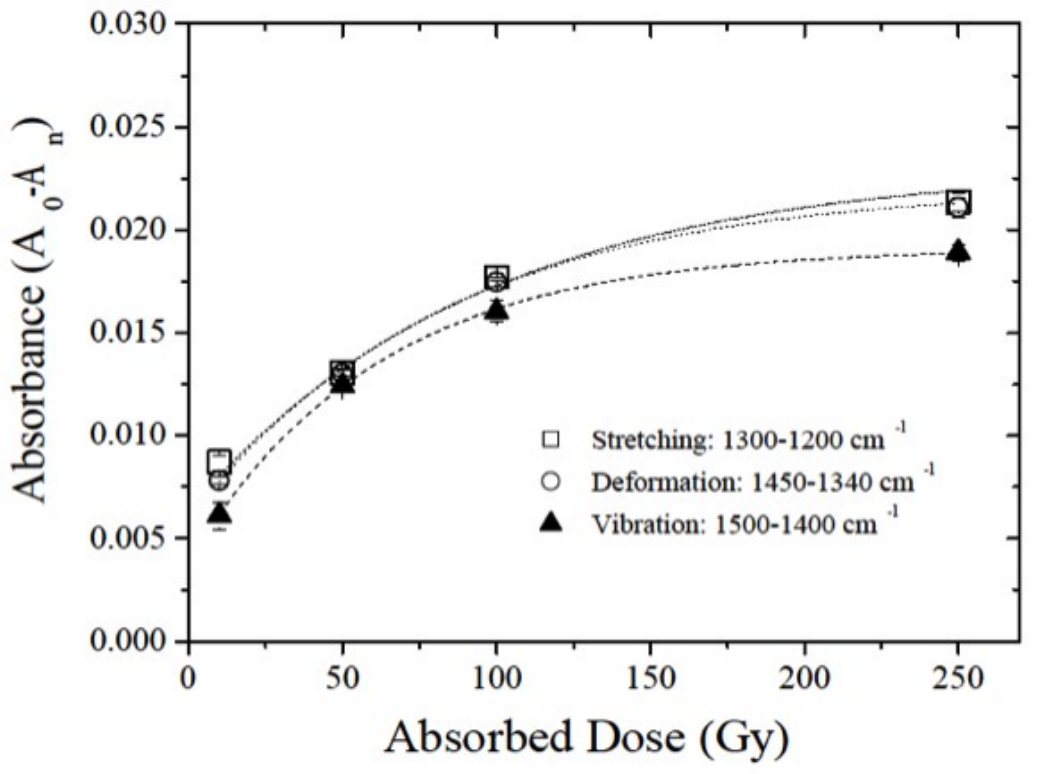

Source: Authors. 


\section{CONCLUSION}

The absorbance peak intensity decreases with increasing absorbed dose in the analyzed infrared region. The absorbance measurements present increasing behavior with the absorbed dose in region from 1000-1500 $\mathrm{cm}^{-1}$ wave number. The stretching and the deformation values are higher than those of vibration, due to the physical propriety (rigidity) of the synthetic rubber. FTIR spectra may be useful in measurements for dosimetry using rubber radiation detectors. These results show that the polybutadiene samples present potential use in measurements of radiation doses.

\section{ACKNOWLEDGMENT}

This research was partially supported by CNPq (Conselho Nacional de Desenvolvimento Científico e Tecnológico) under Grants No. 150775/2014-8, 151013/2014-4 and 165466/2015-4.

\section{REFERENCES}

1. CHMIELEWSKI, A.G.; HAJI-SAEID, M.; AHMED, S. Progress in radiation processing of polymers. Nucl Instr and Meth B, v. 236, n. 1, p. 44-54, 2005.

2. MCKEEN, L.W. "Plastics used in medical devices," in Handbook of polymer applications in medicine and medical devices. Elsevier US, Philadelphia, 2014.

3. MANSHAIE, R.; KHORASANI, S.N.; VESHARE, S.J.; ABADCHI, M.R. Effect of electron beam irradiation on the properties of natural rubber (nr)/styrene butadiene rubber (sbr) blend. Radiat Phys Chem, v. 80, n. 1, p. 100-106, 2011. 
4. ABADCHI, M.R.; JALALI-ARANI, A. The use of gamma irradiation in preparation of polybutadiene rubber nanopowder; its effect on particle size, morphology and crosslink structure of the powder. Nucl Instr and Meth B, v.320, n.1, p.1-5, 2014.

5. ABIONA, A.A.; OSINKOLU, A.G. Gamma-irradiation induced property modification of polypropylene. Int J Phy Sci, v. 5, n.7, p.960-967, 2010.

6. INTERNATIONAL ATOMIC ENERGY AGENCY (IAEA). Dosimetry for Radiation Processing. Viena, Austria. 2000.

7. OLIVEIRA, L.M.; ARAUJO, P.L.B.; ARAUJO, E.S. The effect of gamma radiation on mechanical properties of biodegradable polymers poly(3-hydroxybutyrate) and poly(3hydroxybutyrate-co-3-hydroxyvalerate). Mat Res, v. 16, n.1, p. 195-203, 2013.

8. ZHANG, Y.; ZHAO, S.F.; LI, Y.T.; XIE, L.D.; SHENG, K.L. Radiation effect on styrenebutadiene-styrene copolymer. Nucl Instr and Meth B, v. 266, n.1, p. 3431 3436, 2008.

9. LAL, J.; MARK, J.E. Advances in Elastomers and Rubber Elasticity. Springer US, New York. 1986.

10. PROKOF'EVA, N.I.; SHVARTSBERG, G.I.; SPERANTOVA, I.B. Calculation of the infrared spectrum of 1,4-trans-polybutadiene. J Appl Spectrosc, v. 27, n.3, p. 1185-1188, 1977. 